\title{
Correction to: Risk factors for lymphopenia in patients with relapsing-remitting multiple sclerosis treated with dimethyl fumarate
}

\author{
Fabian Sierra Morales $^{1,3} \cdot$ Igor J. Koralnik $^{1,3} \cdot$ Shiva Gautam $^{2} \cdot$ Soleil Samaan $^{1} \cdot$ Jacob A. Sloane $^{1}(0$
}

Published online: 23 November 2019

๑) Springer-Verlag GmbH Germany, part of Springer Nature 2019

\section{Correction to: Journal of Neurology \\ https://doi.org/10.1007/s00415-019-09557-w}

Unfortunately, the given name and family name of first author was incorrectly tagged in the $\mathrm{xml}$ data, therefore it is abbreviated wrongly as "Morales FS" in Pubmed. The correct given name is Fabian and family name is Sierra Morales. Auhtor name should be abbreviated as Sierra Morales F.

The original article can be found online at https://doi.org/10.1007/ s00415-019-09557-w.

Jacob A. Sloane

jsloane@bidmc.harvard.edu

1 Division of Neuro-Immunology, Department of Neurology,

Beth Israel Deaconess Medical Center, Multiple Sclerosis

Center, Harvard Medical School, 330 Brookline Ave, Ks212,

Boston, MA 02115, USA

2 Division of Biostatistics, Department of Medicine, Beth Israel Deaconess Medical Center, Harvard Medical School, Boston, MA, USA

3 Center for Virology and Vaccine Research, Beth Israel Deaconess Medical Center, Harvard Medical School, Boston, MA, USA 